\title{
Weak Crossover and the Syntax-Phonology Interface
}

\author{
CAliXto AgÜERo Bautista \\ Université du Québec à Trois-Rivières ${ }^{1}$
}

\section{Introduction}

Postal (1971) shows that when a wh-operator is fronted over a position containing a pronoun, the pronoun cannot be understood as a variable bound by the crossing operator. Consider the contrast in (1).

(1) a. Who 1 does his $? * 1 / 2$ mother love $t_{1}$ ?

b. Who $1 \mathrm{t}_{1}$ loves his 1 mother?

In languages like English, a subject $w h$-phrase cannot possibly cross over a pronoun inside an object DP, when fronted, as subjects are structurally higher than objects to begin with. Thus, in (1b) who has not crossed over the object DP containing the pronoun his. (1b) can be understood as a question about the identity of the person $\mathrm{x}$, such that $\mathrm{x}$ loves $\mathrm{x}$ 's mother. In that reading of the sentence, the pronoun is undeniably interpreted as a bound variable, given that its value covaries with that of the wh-phrase. Postal's observation is that whereas the bound variable interpretation (BVI) of the pronoun is available in examples like (1b), the pronoun cannot be so interpreted in (1a). That the BVI of the pronoun is the problem in (1a) is shown by the fact that the sentence is acceptable under a deictic interpretation of the pronoun.

Postal (1971) refers to the data exemplified in (1) as crossover phenomena. Later, Wasow 1979 shows that the deviance found in crossover sentences is greater when the pronoun ccommands the gap than when it doesn't. This is shown in (2).

(2) a. *Who ${ }_{1}$ does he ${ }_{1}$ love $\mathrm{t}_{1}$ ?

b. ?*Who ${ }_{1}$ does his 1 mother love $\mathrm{t}_{1}$ ?

(2a) is worse than (2b). Wasow used the terms strong crossover ( $\mathrm{SCO}$ ) and weak crossover (WCO) as mnemonic terms for the greater deviance of sentences like (2a) with respect to examples like (2b). Since SCO phenomena has been shown in various analyses to violate the intersection of the crossover principle (whatever it is) and other principles of grammar (e.g., Binding Condition C), in the remaining of this article I will only discus WCO phenomena.

1 I thank the audience at the $40^{\text {th }}$ Annual Meeting of the Berkeley Linguistic Society for their questions and comments. 


\section{Previous Accounts}

Chomsky (1976), assuming a rule of Quantifier Raising (QR), later defended in May 1977, points out that the structures of sentences like (1) are entirely parallel to the structure of examples like (3), once the quantifier is raised by QR at the linguistic level of Logical Form (LF), as shown in (4).

(3) a. ?*His mother 1 loves every boy 1 .

b. Every boy loves his $_{1}$ mother.

(4) a. [Every boy $\left[\left[\right.\right.$ his $_{1}$ mother $\left._{2}\right]\left[\mathrm{t}_{2}\right.$ loves $\left.\left.\left.\mathrm{t}_{1}\right]\right]\right]$

b. [Every boy ${ }_{1}\left[t_{1}\right.$ loves [his $s_{1}$ mother]]]

(4a-b) are respectively parallel to (1a-b). Given such parallelism, Chomsky (1976) proposes that the impossibility of the bound variable interpretation of the pronoun in examples like (3a) should follow from whatever principle bans that interpretation in examples like (1a), since both types of examples have essentially the same LFs, namely those in 4, once irrelevant factors are ignored. He proposes the Leftness Condition, which can be stated as in (5).

\section{(5) Leftness Condition (LC):}

A pronoun cannot be linked to a variable to its right.

According to the LC, the problem in structures like (4a) is that the pronoun is linked (coindexed) with the trace $t_{1}$, the variable bound by the operator. Since the trace (i.e. the variable) is to the right of the pronoun, the LC prevents the pronoun from depending of the operator associated with the variable. The LC account of WCO faces both empirical and conceptual problems. I will not review the empirical issues here.

On the conceptual front, a working assumption within generative models of human language has been that in the sub-systems of language dealing with structure-building and semantic interpretation, what Chomsky $(1993,1995)$ respectively calls the computational system $\left(C_{H L}\right)$ and the conceptual intensional $(\mathrm{CI})$ interface, precedence does not play a role. For those components, hierarchy has been shown to be the relevant relation. If so, why should a precedence-sensitive constrain like the LC determine interpretation, a phenomenon of the CI interface?

Reinhart $(1976,1983)$ argues that C-command, and not linear precedence, is the relevant factor determining the distribution of bound pronouns. She argues that pronominal binding is subject to a syntactic condition that can be called the A-binding condition, and which can be stated as in (6). 
(6) A-binding

A pronoun can only be bound from an A-position.

A-positions are those positions where arguments of predicates receive their e-roles or check case or agreement features. A-binding predicts correctly that the pronoun in (4a), corresponding to (3a), cannot be bound by the universal quantifier, given that the latter is a non-argument or $\bar{A}$ position. The same analysis applies mutatis mutandis to the ungrammaticality of (1a), whose LF is identical to (4b), with who in the position of every boy.

The A-binding approach is conceptually more appealing than the LC, since it does away with the precedence relation, which is not expected to play a role in structure-building or in semantic interpretation. It is perhaps for its conceptual appeal that this approach has become very influential. In fact, most theories of WCO that followed the publication of Reinhart's work (i.e., Reinhart 1976; 1983) have incorporated the A-binding insight in one way or another. For instance, Koopman and Sportiche (1983) assume that pronouns bound by phrases in A-positions do not qualify as variables. They then propose the Bijection Principle (BP), a condition preventing A-bar operators from binding more than one variable. The combination of their assumption about the status of pronouns coindexed with A-binders and the BP effectively rules out pronominal-binding scenarios that do not involve A-binding.

Examples of other approaches implementing the A-binding insight include the analyses of Lasnik and Stowell (1991), Jacobson (1999) Ruys (2000), Buring (2004), Schlenker (2004), and Shan and Barker (2006). Bianchi (2001) and Safir (2004) implement the insight in terms of an anti-C-command condition. According to these authors, a constituent depending on a variable or containing a constituent that depends on a variable cannot asymmetrically c-command the given variable.

The common property of these approaches is that they are local in the sense of assuming that the violation resulting in the WCO effect occurs in a local region of the language system (e.g., narrow syntax or the semantic component). Thus, about half of the approaches mentioned in the previous paragraph assume that the WCO effect is a violation of syntax (e.g., Reinhart 1979, 1983; Koopman and Sportiche 1983; Lasnik and Stowell 1991; Bianchi 2001 and Safir 2004), whereas the remaining analyses assume that the relevant violation is semantic (e.g., Jacobson 1999; Ruys 2000; Buring 2004; Schlenker 2004; and Shan and Barker 2006)

A general problem of local approaches in the sense intended in the previous paragraph is that they are too limited in scope. Since the derivation of linguistic expressions involves at least four different components of the language faculty (e.g., the lexicon, the computational system, and the sensorimotor and conceptual intensional interfaces), it is conceivable that a phenomenon that might appear to be local, prima facie, might in the end be the cumulative result of the way in which the four previous components interact during the derivational process. But local constraints, because of their locality, cannot exploit a potential division of labor between the different language components in producing a given phenomenon. Now, since the components of the language faculty do not interact in a random way, it must be the case that there are 
constraints determining exactly how such an interaction proceeds. More importantly, any constraint determining how the components of human language interact are necessarily constrains on the shape of linguistic expressions. Following Chomsky (2005), I will call a condition an architectural constraint if the given condition results from the way the $\mathrm{C}_{\mathrm{HL}}$ maps linguistic expressions, assembled from lexical items, to the interfaces.

Architectural constraints are empirically and conceptually superior to local constraints. Conceptually, architectural constraints instantiate principles of good design that are independent of human language and expected of other subsystems embedded in biological systems, hence such principles need not be attributed to UG. The use of architectural constraints therefore helps achieve the current minimalist goal of reducing UG in order to facilitate the eventual study of the evolution of language. By contrast, local constraints are usually stated in terms of language specific condition. The problem is that since human language seems to be isolated in the biological world, language specific constraints must be attributed to our genetic endowment responsible for language (i.e. UG), hence the use of such constraint goes against general minimalist goals.

Empirically, local constraints are not suitable for capturing linguistic variation within a single language or crosslinguistically. The standard view of linguistic variation is that the component of the language faculty that is responsible for variation is the lexicon. But local constraints, in order to achieve the degree of generality demanded by a generalization, cannot be stated in terms of lexical items, hence any lexical induced variations will be difficult to accommodate in analysis employing such constraints.

\section{Local Accounts of WCO in the Face of Two Paradoxes.}

In this section, I show that the accounts of WCO discussed above face at least two different paradoxes regarding their predictions concerning the crosslinguistic distribution of the WCO effect. The relevant paradoxes are the null-overt (NO) paradox, and the determiner-adjective (DA) paradox. I discuss the first of these paradoxes next.

\subsection{The Null-overt Paradox}

Although a fronted operator cannot bind a pronoun in the subject position of a subject possessive DP, as illustrated in (1a), repeated for convenience as (7), it can certainly do so if the pronoun is null. This is shown in (8) with data from Hungarian. The data is from Kiss (1987) as reported by Georgopolous (1991).

(7) Who 1 does his $? * 1 / 2$ mother love $t_{1}$ ? 
(8) a. $\mathrm{kit}_{\mathrm{i}}$ szeret $\mathrm{t}_{\mathrm{i}}$ az proi anyja

whom loves the motherhis

Whom does hisi $_{\mathrm{i}}$ mother love?

b. mindenkit $t_{i}$ szeret $t_{i}$ az pro $_{i}$ anyja

everybody-ACC loves the mother his

'his mother loves everybody'?

In both of the examples in (8), the displaced operator binds a null pronoun inside the subject possessive DP pro anyja 'his mother'. Native speakers of Hungarian interpret (8a) as a request for information about the identity of the person $\mathrm{x}$, such that x's mother loves $\mathrm{x}$. This is the BVI of the pronoun; precisely the reading that is missing in the English gloss.

The existence of examples like those in (8) and their English counterparts constitutes a paradoxical state of affairs for local accounts of the WCO effect. The problem is that whatever local condition accounts for the presence of the WCO effect in the example in (7), will not extend to cover the absence of the effect in (8) and vice-versa.

The data in (8) cannot simply be dismissed as reflecting an idiosyncratic property of Hungarian: the pattern of null-pronouns escaping the WCO effect is crosslinguistically robust. Van Valin (1987) shows that in head-marking languages, where it is possible to drop a possessive pronoun on the basis of agreement with the head of the possessive DP, the WCO effect disappears with the null pronouns. His example below illustrates the matter perspicuously.

(9) Ø-tha-khóla-ku ki twá wąyąka he?

3-POSS-friend-POSS the who 3sg.see.3sg $Q$

'Who did his friend see?'

The absence of WCO with null pronouns cannot be dismissed as a typologically idiosyncratic property either. It cannot be the case that the WCO effect is somehow suspended in languages with null pronouns, given that phonetically empty pronouns escape the WCO constraint even in languages that allow both overt and null pronouns. Higginbotham's (1980) pro-gate phenomenon shows that this is the case in English. Consider the contrast in (10), modeled after similar examples in Agüero-Bautista (2012).

(10) a. ?*Who, did [his 1 crashing a car] get $t_{1}$ fired?

b. Who 1 did [his 2 crashing a car] get $\mathrm{t}_{1}$ fired?

c. Who 1 did $\left[\mathrm{PRO}_{1}\right.$ crashing a car $]$ get $\mathrm{t}_{1}$ fired?

(10a) shows the classical WCO effect in English. (10b) is a control example, showing that an overt pronoun can occur as the subject of a deverbal gerundive nominal, provided that the pronoun receives a contextually determined value or deictic interpretation. The grammaticality of (10b) in that interpretation shows that there is no problem with the structure of (10a), since that 
structure is identical to that of $(10 \mathrm{~b})$. Rather, the problem with the former example must be the bound variable interpretation of the overt pronoun, which is not possible in a WCO configuration as expected. (10c) is the interesting example, showing that, even in English, a null pronoun can have a bound variable reading in precisely the same WCO-offending configuration of (10a).

Despite the overwhelming crosslinguistic evidence suggesting that null pronouns must in fact be immune to WCO, Safir (2006) has claimed that a WCO effect shows up in the distribution of the null element pro in Spanish. He discusses the example in (11).

(11) *A quien pro dijiste que [la mujer con quien pro habló t] impresiona $\mathrm{t}$ to who (you) said that the woman with which(he) spoke impressed 'Who did you say that [the woman with whom he spoke] impressed t'

A closer look at (11), however, reveals that the deviance of that example might be due to factors not related to WCO. First, the Spanish predicate decir is ambiguous, meaning either 'say' or 'tell'. Like English 'say', decir can take just a direct clausal complement. However, decir can also take an indirect object beside its direct clausal complement. With that argument structure, decir is more like English 'tell' in sentences like Dije a Juan que Susan había llegado 'I told Juan that Susan had arrived.' Given this possibility, after the wh-operator is processed and the predicate decir is encountered, the speaker might naturally tend to posit a gap in the direct object position of decir to be filled with the fronted wh-operator. In such a parse, decir is treated as the equivalent of tell. That parse, however, leads to a dead end, since now there is no wh-phrase to fill the gap in the embedded clause. What this means is that (11) is simply a complex garden-path sentence, taxing the processing abilities of the speaker. In order to control for the garden path factor, decir should be replaced by an unambiguous predicate like pensar 'think', which takes a (single) a clausal complement.

A second problem with (11) is that the subject of the embedded clause is not inverted, although, as shown by Torrego (1984), extraction of argument wh-phrases in Spanish triggers obligatory inversion in every clause that the wh-operator goes through on its way to its landing site.

Interestingly, when the inversion and the garden path problems are taken care of, the deviance associated with (11) disappears.

(12) A quién pro piensas que impresionó [la mujer con quien pro habló t] $t$ to who (you) think that impressed the woman with whom (he) spoke 'Who do you think that [the woman with whom he spoke] impressed t'

(12) is perfectly fine, although a little difficult to interpret out of context. Comprehension of the sentence is facilitated if one adds a continuation like todo el dia 'the entire day' at the end of the bracketed constituent. (13), with more contextual information, clearly shows that pro can have a bound variable interpretation in the configuration of (11). 
(13) A que escritor 1 pro piensas que deshonró [la novela mediocre 2 que pro 1 publicó $\mathrm{t}_{2}$ To which writer 1 (you) think that disgraced [ the novel mediocre $2_{2}$ that he $e_{1}$ published $t_{2}$ (después de la obra maestra)] $\mathrm{t}_{1}$ ?

(After the work master)] $t_{1}$ ?

'Which writer 1 do you think that [the mediocre novel ${ }_{2}$ he $_{1}$ published $t_{2}$ (after his 1 masterpiece)] disgraced $t_{1}$ ?'

(13) is fine despite the fact that the $w h$-operator has been fronted over a DP containing a relative clause dominating the pronoun bound by the operator. (13) allows answers of the form $X$, if $X$ is a personal name referring to an individual who has in fact been acknowledged for writing a masterpiece and the same individual is later disgraced by writing a mediocre novel.

In retrospect, it is not clear if examples with the structure of (11) should yield a WCO effect. For reasons that are not well understood (but see section ?? below), operators can cross over pronouns contained inside relative clauses without triggering a WCO effect. Witness the acceptability of (14).

(14) Who 1 did [the fact that he ${ }_{1}$ came from Arkansas] help $\mathrm{t}_{1}$ become the $42^{\text {nd }}$ president? Answer: Bill Clinton.

What we have seen, then, is that Safir's (2006) data do not constitute a counterexample to the generalization that null pronouns, as opposed to overt ones, escape the WCO effect in the classical WCO-offending configuration. On the one hand, the grammaticality of the Spanish examples in (12)-(13), shows that WCO effect is not present in those examples despite the fact that the null element pro is bound by the crossing $w h$-phrase. On the other hand, the grammaticality of (14) renders Safir's data irrelevant, given that WCO disappears in similar complex structures in English as well.

The relevant examples are those in (7) to (9), where the pronouns are the subject of the possessive DP in subject position of the clause. As we saw above, when the pronoun is overt a WCO effect arises in such a context. However, when the pronoun is null, the WCO effect disappears. Since the structures containing the null pronouns are identical to those containing the overt ones, these data constitute a paradoxical state of affair for local theories of the WCO effect, as any account of the phenomenon based on structural properties will necessarily miss one of the two sets of data.

\subsection{The Determiner-Adjective (DA) Paradox.}

Although overt pronouns in English trigger the WCO effect in the classical crossover configuration of (1), in some languages, at least a sub-class of overt pronouns do not seem to yield the effect in well-known crossover environments. French seems to be such a language. Postal (1993), citing Martinon (1927), gives us the following example. 
(15) Un homme 1 à qui sa jambe fait mal $\mathrm{t}_{1}$

A man to whom 1 his 1 leg makes pain

'A man whose leg hurts'

It is a well-known fact that relative clauses in English show the WCO effect when the relative operator crosses over a pronoun in subject position of a possessive DP (see e.g. Higginbotham 1980; Safir 1986, 2006; Lasnik and Saito 1991; Postal 1993). This is exactly the case of (15), yet, there is no WCO effect in that example. French is not alone in that respect: Spanish behaves similarly. Consider the example below.

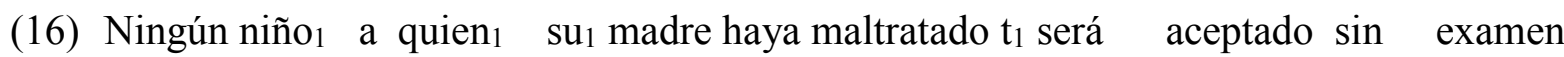

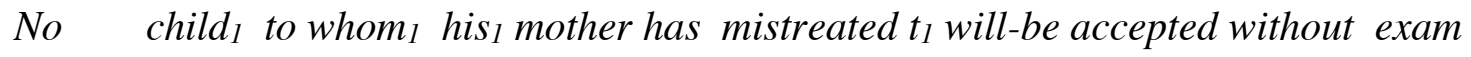
psicológico.

psychological.

'No child who ${ }_{1}$ his 1 mother has mistreated will be accepted without a psychological exam'

These examples do not just reflect a peculiar property of the relative clause construction in Romance. Parallel effects are found in questions. The French examples in (17) are from Postal (1993). The Spanish examples in (18) are my own.

(17) a. Quel homme ${ }_{1}$ crois-tu que sal mère a appelé $\mathrm{t}_{1}$ ? what man $_{1}$ believe-you that his ${ }_{1}$ mother called $t_{1}$ 'What man do you think his mother called?'

b. A quel homme ${ }_{1}$ crois-tu qu'ils ont présenté sa $a_{1}$ voisine $\mathrm{t}_{1}$ ?

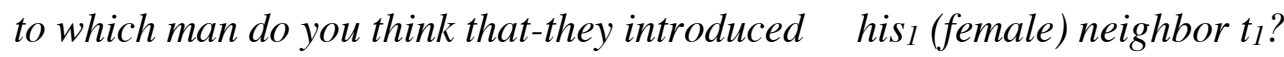
Which $\operatorname{man}_{1}$ do you think that they introduced his 1 female neighbor to $\mathrm{t}_{1}$ ?

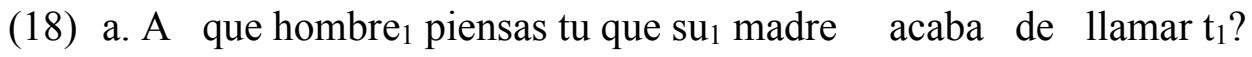
to what man 1 think you that his 1 mother finishes of to-call $t_{1}$ ? What man1 do you think that his ${ }_{1}$ mother just called $\mathrm{t}_{1}$ ?

b. A quien 1 había pensado $\left[\mathrm{su}_{1} \text { padre }\right]_{2} \mathrm{PRO}_{2}$ enviar $\mathrm{t}_{1}$ a rehabilitación. to whom $_{1}$ had thought [her father] $_{2} \mathrm{PRO}_{2}$ to-send to to rehab.? 'Whom 1 had $[\text { her } 1 \text { father }]_{2}$ planned $\mathrm{PRO}_{2}$ to send $\mathrm{t}_{1}$ into rehab?'

The French question in (17a-b) and the Spanish one in (18a) are fully grammatical. These examples, however, must be taken with care in light of findings by Ishii (2006) and myself 
(Agüero-Bautista 2012) showing that when the possessive DP containing the pronoun is in an embedded clause and the crossing $w h$-phrase is in a higher one, the deviance associated with the WCO effect tends to disappear even in English, depending on several factors. For that reason, one should consider monoclausal examples, or biclausal examples like the Spanish one in (18b), where the possessive DP is the subject of the matrix clause, hence the pronoun and the fronted wh-phrase must be clause mates in such an environment. (18b) contrasts with its English gloss in being fully grammatical. The relative clause contexts in (15)-(16) and the Spanish interrogative in (18b) show that for some unknown reasons Romance possessive pronouns like French $s a$ 'his/her' or Spanish su 'his/her' can have a BVI in WCO contexts, unlike what happens with their English counterparts.

Again, these data cannot be dismissed by assuming that WCO is entirely absent in French and Spanish. Some overt pronouns seem to trigger a WCO-like effect in the contexts exemplified in (15)-(18). For instance, one can replace the possessive DP su madre 'his mother' in (16), by the phrase la madre de el 'his mother' (literally: the mother of him), to yield (19).

?*Ningún niño 1 a quien ${ }_{1}$ la madre de él $l_{1}$ haya maltratado $t_{1}$ será aceptado
No child ${ }_{1}$ to whom whe $_{1}$ the mother of him him $_{1}$ has mistreated $t_{1}$ will-be accepted
sin examen psicológico.
without exam psychological.

'No child who ${ }_{1}$ his 1 mother has mistreated will be accepted without a psychological exam'

Unlike (16), (19) is deviant. That the deviance is caused by the binding of the pronoun by the quantifier is shown by the fact that the sentence becomes acceptable if él 'him' is interpreted as a free variable, for instance if it picks out as its value an individual that the speakers points at when uttering the sentence.

French behaves similarly, to the extent that we can construct relevant examples. For instance, in the Quebec dialect of French, it is possible to double a possessive pronoun inside a possessive DP with a normal regular pronoun following the possessive DP in expressions like $s a$ femme à lui 'his wife' (literally: 'his wife of him'). Consider the following contrast.

a. Quelle politicienne ${ }_{1}$ penses-tu que son mari à elle $_{2} \quad$ a trahi $t_{1}$ ? Which politician $_{1}$ think-you that her 2 husband of her 2 has betrayed $t_{1}$ 'Which politician do you think that her husband betrayed t1

b. Quelle politicienne $1_{1}$ penses-tu que son ${ }_{1}$ mari (*à elle $\left.{ }_{1}\right)$ a trahi $\mathrm{t}_{1}$ ? Which politician ${ }_{1}$ think-you that her ${ }_{1}$ husband (of her ${ }_{1}$ ) has betrayed $t_{1}$ 'Which politician 1 do you think that her ${ }_{1}$ husband betrayed $\mathrm{t}_{1}$ ?

The pronoun doubling the possessive DP must get the same value as the possessive pronoun. (20a) shows that if the combination of the possessive pronoun and the double gets a deictic 
value, the sentence is grammatical. When the possessive pronoun is bound by the crossing $w h$ phrase, however, the sentence is grammatical if the double is omitted and ungrammatical otherwise. This indicates that the presence of the double is not compatible with the BVI of the possessive pronoun; suggesting that the overt pronominal double introduces a WCO-like effect that is not present when the possessive pronoun is bound in isolation. These data constitute another paradox for any local structural account of WCO phenomena. The problem is that any structural theory that explains the grammaticality of (16), for instance, will not be able to account for the ungrammaticality of the structurally similar (19). We are thus led to search for an alternative explanation for the WCO phenomena.

\section{Proposal}

The main idea of my proposal is that the WCO effect is a derivational violation of Kayne's (1994) Linear Correspondence Axiom. The violation is derivational because different parts of the architecture of the language faculty conspire to yield the WCO effect. Even pre-theoretically, it is clear that the manifestation of the WCO effect is subject to lexical properties (only a subset of pronominal lexical items in an operator-variable relation triggers the effect), syntactic properties (only a subset of the possible structural configurations mediating an operator and a variable yield a WCO effect), phonological properties (only overt pronouns of a certain kind yield WCO) and semantic properties (the constraint only arises under the BVI). The challenge is to show how this complex of properties, found in the distribution of the WCO effect, follows from the way the $\mathrm{C}_{\mathrm{HL}}$ maps different lexical items to the interfaces.

\subsection{The LCA in a Derivation by Phase Model.}

Kayne (1994) shows that any ordered pair of non-terminal nodes A and B, in a given phrase marker M, such that A asymmetrically c-commands B, can be mapped unto an ordering in which the set of terminal nodes dominated by A precedes the set of terminal nodes dominated by B. His Linear Correspondence Axiom (LCA) is his proposal that this is the way in which hierarchical structure is mapped onto linear order. Kayne takes precedence to be the universal instantiation of linear order. The precedence relation is transitive (i.e., if $\mathrm{xPy}$ and $\mathrm{yPz}$, then $\mathrm{xPz}$ ), total (for all $\mathrm{x}$, $\mathrm{y}$; either $\mathrm{xPy}$ or $\mathrm{yPx}$ ) and antisymmetric (i.e., not (xPy \& yPx)). The LCA is then viewed as a well-formedness requirement on phrase markers: only phrase markers that can be mapped onto a linear ordering without violating any of the formal properties of the ordering relation (i.e. antisymmetry, totality and transitivity) are legitimate syntactic objects.

The minimalist program (MP), with its bare phrase structure technology (see Chomsky 1993, 1995) denies the existence of phrase markers as independent syntactic entities; hence the function of the LCA in a minimalist model of the grammar must be rethought.

In the MP, syntactic objects are put together by recursive applications of the operation Merge. Thus, any antisymmetric properties exhibited by the objects so derived must be the results of the 
inner workings of that operation. In effect, the main consequences of the LCA can be derived from the way Merge works in a multiple spell-out model of the grammar, provided that one assumes that violations of antisymmetry are not tolerated in any wing of the grammar where order matters (e.g., the articulatory-perceptual (AP) system). This is in fact the position taken by Chomsky (1995) and Uriagereka (1999), who assume that order is only required of the PF component, hence they further assume that LCA-like principles are restricted to the AP system. In this article, I argue that the procedure that evaluates compliance with antisymmetry is based on the agreement system. In particular, I argue that probes continuously search their domains for agreeing goals. If a goal is found, it is marked for erasure (E-marked) and must be deleted at spell-out or the derivation is cancelled, since its linearization would instantiate a violation of antisymmetry, as two sets of identical features (i.e., the agreeing features) would be linearized in two different syntactic positions. In order to survive erasure, a goal must be remerged in the first possible spot where it cannot be seen by the searching probe. In general, the first such "blind spot" will be the spec of the searching probe. I take a probe to be any functional lexical item heading a functional phrase. The search domain of a probe is just the c-command domain of the given probe as restricted by the phase impenetrability condition (PIC) of Chomsky (2001). An immediate consequence of this view of agreement is that it derives at once the fact that copies must be phonetically empty and that their antecedents must be in a spec-head agreement configuration. A second consequence is that it derives the $\mathrm{WCO}$ effect triggered by determiner pronouns, as we shall see in the following section.

\subsection{Why Determiner Pronouns Trigger WCO}

I assume that determiner pronouns require NP complements as all determiners do. Furthermore, I will assume that since the NP complement of a determiner pronoun is phonologically deleted, the information it conveys must be recovered from the (syntactic) context in which it appears, given the relevance of general conditions on the recoverability of information constraining deletion (cf. Elbourne 2001, 2005). Based on these facts, I argue that in the BVI of a determiner pronoun, the NP complement of the pronoun is a copy of the NP of the antecedent DP. How can the pronoun end up with a copy of the antecedent DP? A plausible scenario (and one that I will assume here) is that the pronoun and the determiner of the antecedent DP are parallel-merged with the same NP à la Citko (2005). If the process occurs before any phase head is merged, no violation of cyclicity or the Extension Condition will ensue. Under this view, the sentence in (21a) must go through the stage in (21b)

(21) a. Which $\operatorname{man}_{1}$ does his 1 mother love $t_{1}$ ?

b. Merge 〈which, man〉; Merge 〈he, man〉

At the stage in (21b) Merge applies in parallel to the pairs 〈which, man〉 and 〈he, man〉 creating the DPs which man and he man respectively. When the sentence is finally put together, its 
ultimate representation looks like (22) where unpronounced copies are indicated with strikethrough font. I take the liberty to represent irrelevant copies as traces.

(22) $\left[\right.$ CP which $\operatorname{man}_{1}\left[\mathrm{C}\right.$ ' does $\left[\mathrm{IP}\left[\mathrm{DP}\left[\mathrm{DP} \text { he }{ }_{1} \text { man }\right][\mathrm{D} \text { ' 's mother }]\right]_{2}\left[\mathrm{vP}\right.\right.$ tl t $\mathrm{t}_{2}$ love which $\left.\operatorname{man}_{1}\right]$

The problem of (22) is that the pronoun spells out the $\varphi$-features of its complement NP, but since its elided complement is a part of the antecedent, the set of $\varphi$-features of the antecedent ends up linearized in two different positions: the site of the antecedent in Spec, CP, and the site of the pronoun in Spec of the subject possessive DP. When the probe $\mathrm{C}^{0}$ searches it domains for agreeing goals, it can see the pronoun in the same way that it can see the deleted copy of which man in the position of $t_{1}$ in (22). The copy of which man can be deleted, as the extra copy of that DP in Spec, CP makes the structure comply with the condition on the recoverability of information constraining ellipsis. However, no such condition can be met in the case of the pronoun, as there is just a single copy of this item in (22). Deletion, therefore, cannot take place and the example inevitably violates antisymmetry, hence it is unacceptable.

Crucially, in (22) the pronoun is in the search domain of the agreeing probe, the $\mathrm{C}^{0}$ that agrees with the antecedent and by transitivity with the pronoun. This is because no intervening phase head is located between the pronoun and the antecedent. ${ }^{2}$ This analysis predicts that if the pronoun were embedded under a phase head, the probe could not "see it" (reach it) and the resulting example should be fully grammatical even on the phase of agreement. This prediction is borne out: witness the grammaticality of examples like (1b), repeated here as (23a), with the structure in (23b).

(23) a. Who $\mathrm{t}_{1}$ loves his $\mathrm{s}_{1}$ mother?

b. [CP who C' [IP whe [vP whe [v'v [DP [DP he persen]'s mother]]]]

In the structure in (23b), $\mathrm{C}^{0}$ cannot see the pronominal DP, as the latter is encapsulated within the vP phase. In other words, the pronoun in the structure in (23b), corresponding to the sentence in (23a), is not in the search domain of the agreeing probe. Although it agrees with the probe, it

\footnotetext{
${ }^{2}$ Notice that the same analysis applies to structures like those in (4a), repeated here as (i), corresponding to sentences like those in (ii).

(i) $\left[\right.$ Every boy $1\left[\left[\right.\right.$ his $_{1}$ mother $\left._{2}\right]\left[\mathrm{t}_{2}\right.$ loves $\left.\left.\left.\mathrm{t}_{1}\right]\right]\right]$

(ii) $\mathrm{His}_{1}$ mother $_{2} \mathrm{t}_{2}$ loves every boy 1

I assume that the covert copy of the quantifier is in the spec of an agreeing head that is higher than the pronoun. The given head, whatever it may be, agrees with the pronoun by transitivity. Since the pronoun is within the search domain of the relevant head, as no phase head intervenes between the two, the copy of the pronoun is subject to Emarking exactly as it is in the context of wh-extraction.
} 
occurs in a "blind spot," hence the grammar has not basis for E-marking the structure. Thus, the acceptability of such examples follows naturally.

\subsection{Solving the Null-Overt Paradox.}

The present analysis solves the puzzle of why null pronouns do not trigger the WCO effect. The answer is an immediate consequence of this account: null pronouns do not trigger the WCO effect because they are lexically null, hence they trivially comply with the requirement of Emarking. Nothing more needs to be said about such cases. Notice that this analysis predicts that if phonological deletion of a determiner pronoun is somehow possible, in a WCO configuration (e.g., because the requirement on the recoverability of deleted material is somehow met), the bound variable interpretation of the pronoun should be possible. This prediction is in fact borne out. Consider the examples in (24a), from Williams (1994), and those in (24b-c) modeled after (24a).

(24) a. His town major executed a friend of mine.

b. ?*His town major executed a friend of mine, but I don't know exactly who 1 his 1 town

major executed.

c. His town major executed a friend of mine, but I don't know exactly who 1 his t $_{\text {town }}$ major executed.

Williams notes that (24a) is a possible case of backward anaphora, provided that the indefinite receives a very specific interpretation. Fodor and Sag (1982) and researchers working within the discourse representation framework (e.g., Heim 1982, Kamp 1981) have assumed that indefinites could be referential entities, so the grammaticality of (24a) could follow from an interpretation of the pronoun via a strategy other than the BVI, hence the WCO constraint would be irrelevant. Both (24b-c) could occur naturally under a phrase like I heard that. In such a context, my consultants judged (24b) deviant and (24c) acceptable. The contrast follows naturally from the present analysis: $(24 \mathrm{c})$ is a sluicing structure in which the pronoun together with the whole containing IP has been deleted in compliance with the E-marking requirement discussed above.

\subsection{Solving the Determiner-Adjective Paradox}

The present analysis can also account for the fact that possessive pronouns do not trigger the WCO effect in French and Spanish as we saw in section 3. Consider again the example in (16), repeated below for convenience. 
(25) Ningún niño ${ }_{1}$ a quien su $_{1}$ madre haya maltratado $t_{1}$ será aceptado sin examen No child to $_{1}$ whom h his $_{1}$ mother has mistreated $t_{1}$ will-be accepted without exam psicológico.

psychological.

'No child who ${ }_{1}$ his ${ }_{1}$ mother has mistreated will be accepted without a psychological exam'

This example is acceptable in Spanish and unacceptable in English, as shown by the deviance of the gloss. Why should there be such a difference between possessive pronouns and other regular Spanish pronouns like el 'him', which do trigger a WCO-like effect? I believe the answer to this question is to be found in the categorial status of Romance possessive pronouns. I believe that one can plausibly assume that Romance possessive adjectives are introduced into the derivations as adjectives (i.e., as $\mathrm{A}^{0} \mathrm{~s}$ lexical items). In modern Italian, for instance, possessive pronouns can be preceded by articles in phrases like la sua mama 'his mother' (literally: the his mother). In some dialects of Spanish, possessive pronouns can occur with articles and even in standard Spanish, possessives pronouns can occur with demonstratives in expressions like esta su casa 'this his house' (see Picallo and Rigau 1999). Historically, Romance possessive pronouns were adjectives. Thus in French, expressions like un mien livre 'a book of mine' (literally: a my book) were still possible almost at the beginning of the $20^{\text {th }}$ century. Perhaps, more significant is the fact that possessive pronouns in all Romance languages still preserve the agreement pattern of adjectives. Thus, although English pronouns agree in number and gender with their antecedents, Romance pronouns agree in number and gender with the NP that follows them as shown in (26).

(26) Mary saw her books.

(27) Maria vio sus libros

M. saw PRON-pl book-pl

'Maria saw her books'

(28) Marie et Amelie ont vu son livre

$M$. and A. have-seen PRON-s-m book-s-m.

'Marie and Amelie saw their book'

In (26), her agrees in gender and number with the antecedent DP Mary. In the Spanish example in (27), on the other hand, the possessive pronoun sus agrees in number with the following NP and not with the antecedent Maria. Similarly, in the French example in (28), the pronoun agrees in number and gender with the following NP: Marie et Amelie is a semantically plural DP bearing feminine gender, and yet the pronoun is singular and masculine like the NP that follows it. If possessive pronouns are merged as A0s and then subsequently move to D in French and 
Spanish, we capture the fact that they cannot co-occur with articles in these languages while preserving the agreement pattern of adjectives. I will assume that much in what follows.

It turns out that with such an assumption in place, the behavior of Romance possessive pronouns with respect to the WCO effect follows automatically from the present analysis. Since A0s do not select NP complements, possessive pronouns of such categories cannot possibly be parallel merged with the NP of their complement or any other complement NP for that matter. Thus, the NP that follows such pronouns cannot be a copy of the NP of their antecedent. The set of $\varphi$ features spelled out by such pronouns is thus different from the set of $\varphi$-features of the antecedent DP, hence their realization does not violate antisymmetry.

\section{$5 \quad$ Extension}

The present analysis can be extended to cover a number of related phenomena that I cannot cover here, unfortunately. I will mention, however, two such phenomena. One is the phenomenon that Montalbetti (1984) addresses under the rubric of the Overt Pronoun Constraint (OPC). The other is the phenomenon discussed by Chomsky (1981) in proposing his Avoid Pronoun Principle. Montalbetti notices that in contexts in which it is possible to use an overt or a null pronoun in null subject languages, the overt pronoun cannot have a BVI. Montalbetti proposes the OPC, which can be defined as in (29).

(29) The Overt Pronoun Constraint:

In contexts in which an overt/null alternation obtains, an overt pronoun cannot be bound.

The OPC has been argued to be responsible for contrasts like the one in (30).

[Nadie 1 dijo [que el $*_{1 / 2} /$ pro $_{1 / 2}$ era comunista]

No one ${ }_{1}$ said that he $* 1 / 2 /$ pro $_{1 / 2}$ was communist

'No one ${ }_{1}$ said that he 1 was a communist'

In (30), the null element pro in the embedded clause can be bound by the quantificational subject of the matrix clause no one or it can refer to some salient entity in context. However, a BVI for the overt pronoun $e l$ 'him' is impossible in the same context. Notice that this configuration is not a WCO context, since both the quantifier and its trace c-command the pronoun to start with, hence a different principle was required at the time the OPC was proposed in order to account for such cases. Nevertheless, there are both conceptual and empirical problems regarding the OPC. On the conceptual front, the principle is at most a description of the facts without a principled explanation as to why the grammar should obey such a condition. On the empirical front, it has been reported that some pronouns in null subject languages can sometimes have a BVI in the same context in which a null pronoun can also occur. For instance, Gürel (2003) discusses the 
behavior of the overt Turkish pronoun kendisi 'self' which is in free variation with the null element pro in violation of OPC.

A consequence of the current analysis of $\mathrm{WCO}$ is that it makes overt determiner pronouns costly. Given their propensity for violating antisymmetry under the BVI, the natural habitat for such pronouns are contexts of coreference. However, as Reinhart $(2000,2006)$ argues, successful coreferential uses of pronouns are subject to Rule I, a principle that induces reference set computation (global comparison of truth-conditionally equivalent alternatives), a process that is computationally costly. As a result of this, both null pronouns and overt pronouns of the categories of nouns and adjectives are less costly than overt pronouns of the category of determiners, as the formers cannot violate antisymmetry. A plausible hypothesis, then, is that OPC effects are the result of the less costly pronouns preventing the use of the computationally costly overt determiner ones. This view of OPC effects is conceptually superior to previous ones: the relevant effects follow from general principles of computational economy, hence no language specific principle is needed and we thus remove another barrier preventing the achievement of the minimalist goal of simplifying UG. This view of OPC is also conceptually superior to its predecessors. For instance, it can account for the exceptionality of kendisi in Turkish. Gürel (2003) translate this element as 'self', noting that as an adjective this pronoun means own. I take Gürel's notes to show that kendisi 'self' is either a noun or an adjective. In either case, this element will not be able to be parallel merged with the NP of its antecedent. It thus cannot violate antisimmetry, hence it must be as computationally cheap as null pronoun. It is predicted, therefore, not to show OPC-like effects.

The effects related to the so-called Avoid Pronoun Principle follow in the same way. Consider the following contrast from Chomsky (1981).

(31) a. John would much prefer [his going to the movie]

b. John would much prefer [his (own) book]

Chomsky notes that the pronoun in (31b) can refer to John or to somebody else, but that in (31a), there is a strong preference for interpreting the pronoun to mean somebody other than John. The possibility of coreference between John and the he of his book in (31b) shows that the bracketed constituent in (31) is not a context of disjoint reference. Chomsky notices that in (31a), but not in (31b), the null element PRO can occur in the position of the pronoun. He then conjectures that "the choice of reference" in (31a) "is dictated not by the disjoint reference principle, but rather by a principle that we may state in the most general terms as ...Avoid Pronoun" (p. 65). Like the OPC effects Avoid Pronoun effects also follow from the present analysis: whenever a computationally cheaper pronoun can occur in the same context of a computationally costly one, the computationally cheaper item will be chosen in accordance with general principles of computational economy. 
I am now in a position to answer a question that has sometime come up during my presentation of the previous data. Consider again the example in (19), repeated below for convenience.

?*Ningún niño ${ }_{1}$ a quien ${ }_{1}$ la madre de él $l_{1}$ haya maltratado $t_{1}$ será aceptado No $\quad$ child $_{1}$ to whom ${ }_{1}$ the mother of him ${ }_{1}$ has mistreated $t_{1}$ will-be accepted sin examen psicológico.

without exam psychological.

'No child who ${ }_{1}$ his 1 mother has mistreated will be accepted without a psychological exam'

The question is the following. Since I have claimed that pronouns embedded inside a phase head cannot be seen by an agreeing searching probe, as they will not be in the search domain of the given probe, does my theory of WCO predict that examples like (32) should be acceptable if DPs are phases? The answer to that question is that the present analysis does not necessarily predict acceptability in the relevant contexts DPs are phases. Rather, for such environments, the current analysis predict the acceptability of determiner pronouns, only if there are no truth-conditionally equivalent examples involving computationally less costly items. From this perspective, the ungrammaticality of (32) follows from the fact that there is a truth-conditionally equivalent example involving the computationally cheap pronoun su 'his', namely example (25).

\section{Conclusion}

I have argued that the WCO effect reduces to a detectable violation of antisymmetry. In particular, I have argued that a determiner pronoun that agrees with a head that is the sister to the antecendent DP is marked for erasure at Spell-out by the system. Unless the pronoun is deleted by spell-out, something that is possible only if allowed by the standard conditions on the recoverability of information constraining ellipsis, the derivation is cancelled. We saw that the present approach can solve two paradoxes that arise in other alternative analyses. In addition, the account is principled in the sense that it reduces the phenomenon to bear output conditions. That is, the analysis pins the WCO effect to properties of syntax-phonology interface, without positing language or binding specific principle, and in fact, reducing some of the related principles invoked for accounting the behavior of some overt pronouns. Admittedly, many questions remain, but the approach is no doubt promising, and I intend to continue pursuing it in future research. 
Agüero-Bautista, Calixto. 2013. On the Proper Formulation of the Overt Pronoun Constraint. Ms., Université du Québec à Trois-Rivières

Bianchi, Valentina. 2001. Antisymmetry and the Leftness Condition: Leftness as Anti-ccommand. Studia Linguistica 55: 1-38.

Büring, Daniel. 2004. Crossover Situations. Natural Language Semantics 12: 23-62.

Chomsky, Noam. 1976. Conditions on Rules of Grammar. Linguistic Analysis 2: 303-351.

Chomsky, Noam. 1981. Lectures on Government and Binding. The Hague: Mouton de Gruyter.

Chomsky, Noam. 1993. A Minimalist Program for Linguistic Theory. In Ken Hale and Samuel J. Keyser. The View from Building 20. Cambridge, MA.: MIT Press.

Chomsky, Noam. 1995. The Minimalist Program. Cambridge, MA.: MIT Press.

Chomsky, Noam. 2005. Three Factors in Language Design. Linguistic Inquiry 36: 1-22.

Citko, Barbara. 2005. On the nature of Merge: Internal Merge, External Merge, and Parallel Merge. Linguistic Inquiry 36: 475-496.

Elbourne, Paul. 2001. On the Semantics of Pronouns and Definite Articles. In Roger Billerey and Brook Danielle Lillehaugen, eds., Proceedings of WCCFL 19, 83-96. Somerville, MA.: Cascadilla Press.

Elbourne, Paul. 2005. Situations and Individuals. Cambridge, MA.: MIT Press.

Fodor, Janet Dean and Ivan Sag. 1982. Referential and Quantificational Indefinites. Linguistics and Philosophy 5: 355-398.

Georgopoulos, Carol. 1991. Syntactic Variables. Resumptive Pronouns and A' Binding in Palauan. Dordrecht: Kluwer Academic Press.

Gürel, Ayse. 2003. Is the Overt Pronoun Constraint Universal? Evidence from L2 Turkish. In Juana M. Liceras et al., eds., Proceedings of the $6^{\text {th }}$ Generative Approaches to Second Language Acquisition. 130-139. Somerville, MA.: Cascadilla Press.

Jacobson, Pauline. 1999. Towards a Variable Free Semantics. Linguistic and Philosophy 22: 117-184.

Heim, Irene. 1982. The Semantics of Definite and Indefinite Noun Phrases. PhD dissertation, University of Massachusetts, Amherst.

Higginbotham, James. 1980. Pronouns and Bound Variables. Linguistic Inquiry 11, 679-708.

Ishii, Toru. 2006. A Nonuniform Analysis of Overt wh-movement. Linguistic Inquiry 37:155167.

Kayne, Richard. The Antisymmetry of Syntax. Cambridge, MA.: MIT Press.

Kamp, Hans. 1981. A Theory of Truth and Semantic Representation. In J. Groenendijk, T. Janssen and M Stokhof, eds., Formal Methods in the Study of Language: Proceedings of the Third Amsterdam Colloquium, Part I, 277-321. Amsterdam: Mathematical Center.

Koopman, Hilda and Dominique Sportiche. 1983. Variables and the Bijection Principle. The Linguistic Review 2: 139-160.

Lasnik, Howard and Tim Stowell 1991. Weakest Crossover. Linguistic Inquiry 22: 687-720. Martinon, Phillipe. 1927. Comment on Parle en Français. Paris: Librairie Larousse. 
May, Robert. 1977. The Grammar of Quantification. Cambridge, MA.: MIT Press. Montalbetti, Mario. 1984. After binding. PhD dissertation: Cambridge, MA: MIT Press.

Picallo, Carmen and Gemma Rigau. 1999. El Posesivo y las Relaciones Posesivas. In Ignacio Bosque and Violeta Demonte, eds., Gramatica Descriptiva de la Lengua Española. Vol. 1., 973-1023, Madrid: Editorial Espasa Calpe.

Postal, Paul. 1971. Cross-over Phenomena. New York: Holt, Rinehart and Winston.

Postal, Paul. 1993. Remarks on Weak Crossover Effects. Linguistic Inquiry 24, 539-556.

Reinhart, Tanya. 1976. The Syntactic Domain of Anaphora. PhD dissertation, MIT.

Reinhart, Tanya. 1983. Anaphora and Semantic Interpretation. Chicago: University of Chicago Press.

Reinhart, Tanya. 2006. Interface Strategies: Optimal and Costly Computations. Cambridge, MA.: MIT Press.

Ruys, E. G. 2000. Weak Crossover as a Scope Phenomenon. Linguistic Inquiry 31: 513-539.

Safir, Ken. 2006. The Syntax of (In)dependence. Cambridge, MA.: MIT Press.

Schlenker, Philippe. 2005. Non-redundancy: Towards a Semantic Reinterpretation of Binding theory. Natural Language Semantics 13: 1-92.

Shan, Chung-Chieh, and Chris Barker. 2006. Explaining Crossover and Superiority as Left-toRight Evaluation. Linguistics and Philosophy 29: 91-134.

Torrego, Esther. 1984. On Inversion in Spanish and some of its Effects. Linguistic Inquiry 15: 103-129.

Uriagereka, Juan. 1999. Multiple Spell-Out. In Samuel D. Epstein and N. Hornstein, eds., Working Minimalism, 251-282. Cambridge, MA.: MIT Press.

Van Valin, Robert D. 1987. The Role of Government in the Grammar of Head-Marking Languages. International Journal of American Linguistics 53: 371-397.

Wasow, Thomas. 1979. Anaphora in Generative Grammar. Ghent: E. Story-Scientia.

Williams, Edwin. 1994. Thematic Structure in Syntax. Cambridge, Mass.: MIT Press. 